\title{
Comparison of Enhanced Solubility Profile Analysis of Thermodynamic Parameters and Pharmacokinetic Profile Related to Tamoxifen Citrate Solubilisation
}

\author{
Laboni Mondal, Biswajit Mukherjee*, Shreyasi Chakraborty, Sanchari Bhattacharya, Iman Ehsan, Soma \\ Sengupta and Murari M Pal \\ Department of Pharmaceutical Technology, Jadavpur University, India
}

Received Date: June 14, 2018; Published Date: July 09, 2018

*Corresponding author: Biswajit Mukherjee, Department of Pharmaceutical Technology, Jadavpur University, Kolkata, West Bengal, India, Email:biswajit55@yahoo.com

\begin{abstract}
The aim of this study was to investigate the improvement of solubility of a poorly water soluble drug tamoxifen citrate (TC) by various methods such as cosolvency, micellisation, and complexation. Cosolvents (ethanol, polyethylene glycol-400), surfactants [polyoxyethylene sorbitan monooleate (Tween-80), poloxamer-407 and poloxamer-188], and cyclodextrins [ $\beta$-cyclodextrin (BCD) and hydroxypropyl- $\beta$-cyclodextrin (HPBCD)] were used as solubilizing agents in this study. Solubility improvement approaches showed variable degrees of solubility improvement of TC. Among the solubilizing agents used, the modified $\beta$-cyclodextrin was found to be the most effective. The solubility of TC was enhanced to $6.31 \mathrm{mmolL}^{-1}$ in water (about 7.1 fold solubility improvement) using $0.05 \% \mathrm{~m} / \mathrm{v}$ hydroxy propyl- $\beta$-cyclodextrin. Different thermodynamic parameters, enthalpy and entropy, were analyzed for solubility enhancement of TC with different cyclodextrins which showed enthalpy not the entropy was the driving force for TC solubilisation. The less positive enthalpy of BCD complexation than HPBCD complexation signifies the higher solubilising efficacy of HPBCD. Pharmacokinetic study was performed using HPBCD as solubility enhancer at its optimized concentration which also resulted in improved bioavailability when compared to the bioavailability obtained with free tamoxifen.
\end{abstract}

Keywords: Tamoxifen citrate; Solubility; Cosolvent; Surfactant; Cyclodextrin; Pharmacokinetic

\section{Introduction}

Tamoxifen citrate (TC) is an antiestrogenic drug and is first choice treatment of breast cancer in both pre- and post-menopausal women. The antiestrogenic effects may be related to its ability to compete with estrogen for binding sites in target tissues such as breast [1]. Chemically, TC is the isomer of a triphenylethylene derivative. The chemical name is (Z) 2-[4-(1,2-diphenyl-1-butenyl) phenoxy]-N,Ndimethylethanamine-2-hydorxy-1,2,3-propane tricarboxylate. Following a single oral dose of $20 \mathrm{mg}$ tamoxifen, an average peak plasma concentration of $40 \mu \mathrm{g} \mathrm{L}^{-1}$ (range 35 to $45 \mathrm{ng} \mathrm{ml}^{-}$ ${ }^{1}$ ) occurred in 4-7 h after dosing [2,3] and this indicates poor bioavailability of the drug. Poorly water-soluble drugs often provide limited bioavailability if dissolution is the rate-limiting step in overall oral absorption process [4]. Since TC is poorly soluble in water (equilibrium solubility inwater at $37^{\circ} \mathrm{C}$ is 0.5 $\mathrm{mg} \mathrm{ml}^{-1}$ ) [5], it is , therefore, important to improve its solubility to ameliorate its bioavailability [6].

Although there has been enormous amount of research works performed using different techniques of solubilisation, yet a comparative profile is very scarce. In this study, the effect of different solubilisation approaches such as micellar solubilisation, complexation by cyclodextrins and cosolvency on the aqueous solubility of TC has been presented in a comparative approach. An attempt has been made to provide an insight into the mechanism of solubilisation of TC particularly by complexation based on analysing thermodynamic parameters, since complexation was found to be the most successful approach among the methods tried.

\section{Experimental}

\section{Materials}

Poly (ethylene glycol) 400 (SRL Pvt. Ltd., Mumbai, India), $\beta$-cyclodextrin (Hi Media Laboratories Pvt. Ltd., Mumbai, India), tween-80 (S.d. Fine Chemical Limited, Mumbai, India), absolute ethanol (Merck Ltd., Mumbai, India) were obtained commercially. Hydroxypropyl- $\beta$-cyclodextrin, poloxamer-407, poloxamer-188 were purchased from Sigma-Aldrich, Bengaluru, India. TC (Khandelwal Laboratories Pvt. Ltd., Mumbai, India) was a gift sample. 


\section{Phase Solubility Study}

In each of the different approaches (cosolvency, micellisation, and complexation) of solubilisation, solubility of TC was determined by placing an excess amount of TC $(10 \mathrm{mg})$ in water $(5$ $\mathrm{ml}$ ), in different test tubes containing increasing concentrations (Table1) of various cosolvents, surfactants and the complexation agents so that the total volume in each case remained to $5 \mathrm{ml}$. Three sets of sample vials were prepared for each particular solubilising agent. The test tubes were shaken mechanically in a shaker water bath at $37^{\circ} \mathrm{C}$ for $48 \mathrm{~h}$. At equilibrium (after 2 days, as preliminary studies showed that this period of time was sufficient to ensure saturation at $37^{\circ} \mathrm{C}$ ), aliquots were removed, centrifuged for $10 \mathrm{~min}$ at $10000 \mathrm{rpm}$. After proper dilution with water the samples were analyzed spectrophotometrically at $275 \mathrm{~nm}$ using Shimadzu UV/Vis spectrophotometer (Japan) [7] taking appropriate blank solution. The cosolvents used were ethanol, poly (ethylene glycol) 400 and glycerine. The surfactants were polyoxyethylene sorbitan monooleate (Tween 80), poloxamer-407 and poloxamer-188. The complexation ligands were $\beta$-cyclodextrin (BCD) and hydroxypropyl- $\beta$-cyclodextrin (HPBCD).

\section{Thermodynamic Parameters for Different Cyclodex- trin Concentrations}

Thermodynamic analysis was performed by measuring the solubility measurement with BCD and HPBCD concentration $(0.05 \% \mathrm{~m} / \mathrm{v}$ to $0.5 \% \mathrm{~m} / \mathrm{v})$ at different temperatures $(300,310$ and $320 \mathrm{~K}$ ) (Tables $2 \& 3$ ). Rest of the procedure was same as the phase solubility study. Gibbs and van't Hoff equations were used to estimate the thermodynamic parameters, enthalpy $\left(\Delta \mathrm{H}^{\circ}\right)$, entropy $\left(\Delta \mathrm{S}^{\circ}\right)$ and Gibbs free energy $\left(\Delta \mathrm{G}^{\circ}\right)$.

The general form of van't Hoff equation for calculation of thermodynamic parameters:

$$
\ln \mathrm{K}=\Delta \mathrm{S}^{\circ} / \mathrm{R}-\Delta \mathrm{H}^{\circ} / \mathrm{RT}
$$

or

$$
\log \mathrm{K}=-\left(\Delta \mathrm{H}^{\circ} / 2.303 \mathrm{R}\right) 1 / \mathrm{T}+\Delta \mathrm{S}^{\circ} / 2.303 \mathrm{R}
$$

The Gibbs equation gives the values of $\left(\Delta \mathrm{H}^{\circ}\right)$ and $\left(\Delta \mathrm{S}^{\circ}\right)$ and therefore, the values of $\left(\Delta \mathrm{G}^{\circ}\right)$ were calculated in each case from the equation.

$$
\Delta \mathrm{G}^{\mathrm{o}}=\Delta \mathrm{H}^{\mathrm{o}}-\mathrm{T} \Delta \mathrm{S}^{\mathrm{o}}
$$

For a plot of $\ln \mathrm{K}$ versus $1 / \mathrm{T}$, slope $=-\Delta \mathrm{Ho} / \mathrm{R}$ and intercept $=$ $\Delta \mathrm{So} / \mathrm{R}$ were calculated.

Where, K (equilibrium constant) represents either S (drug inherent solubility) or $\mathrm{K}_{1: 1}$ (equilibrium constant considering 1:1 complex formation). The values of $S$ were initially estimated from the phase solubility diagrams) [8].

\section{Pharmacokinetic Study by LC-MS/MS}

Swiss albino mice (either sex, 25-30 g) were purchased from registered breeders, and were given normal standard diet with tap water ad libitum. Animals were kept under a $12 \mathrm{hrs}$ light dark cycle. The animals were maintained in this condition for at least one week prior to the experiment. All experiments were conducted as per the guidelines of the animal ethics committee (AEC), Jadavpur University, Kolkata.

Animals were divided into two groups (10 animals in each group) and fasting condition for at least $24 \mathrm{~h}$ prior to the experiment. Animals from the free drug group (FD) were given tamoxifen citrate at $10 \mathrm{mg} / \mathrm{kg}$ oral dose and animals of the test group (CD) were given HPBCD (as a solubility enhancer at the concentration of $0.5 \% \mathrm{w} / \mathrm{v}$ ) along with $\mathrm{TC}$ in an equivalent oral dose of $10 \mathrm{mg} / \mathrm{kg}$. mixing in water. After oral dosing mice were anaesthetized with diethyl ether. Blood samples were collected by heart puncture technique at various time points from $0.25 \mathrm{~h}$, $0.5 \mathrm{~h}, 1 \mathrm{~h}, 2 \mathrm{~h}, 4 \mathrm{~h}, 8 \mathrm{~h}$ and $24 \mathrm{~h}$. Blood samples were centrifuged at $6000 \mathrm{rpm}$ for $5 \mathrm{~min}$ and plasma were collected and stored at $-80^{\circ} \mathrm{C}$ until further study by LC-MS/ MS.

\section{LC-MS/MS Assay}

Working stocks of TC were prepared by serial dilution in HPLC grade methanol. Working stocks and blank plasma were spiked to prepare calibration control (CC) and quality control (QC) samples. Liquid liquid extraction (LLE) technique was used for the extraction of CC, QC and test samples.

The plasma concentrations of TC in both the groups were determined by LC-MS/MS assay using a method described by Choi and Kang [9]. At first, $0.05 \mathrm{ml}$ butyl paraben (IS) of concentration $8 \mu \mathrm{g} / \mathrm{ml}$ in methanol was added to $0.2 \mathrm{ml}$ acetonitrile and $0.2 \mathrm{ml}$ of plasma sample. This mixture was vortexed and centrifuged at 13,000 rpm for $10 \mathrm{~min}$ and $0.05 \mathrm{ml}$ of the supernatant was loaded to LC-MS/MS (LC: Shimadzu Model 20AC, MS: AB-SCIEX, Model: API 4000, Software: Analyst 1.6) for analysis. Plasma data were plotted against time and PK parameters were determined by WinNonlin software (Certara,UK).

\section{Results and Discussion}

\section{Cosolvency}

Figure 1 shows straight lines in semi-logarithmic plot of TC solubility vs. volume fractions of the experimental cosolvents. Solubility study of TC with different concentrations of the cosolvents, ethanol and PEG- 400 at $37^{\circ} \mathrm{C}$ showed that efficiency of ethanol $(15 \% \mathrm{~V} / \mathrm{V})$ as cosolvent was higher $(6.10$-fold $)$ than that of $15 \%$ PEG-400 (5.62-fold) compared to the inherent solubility of TC in water.

Cosolvents are widely used in pharmaceutical industry for solubilisation purpose. They work by reducing hydrogen bond density of aqueous system and create a less polar environment in bulk [10]. This results in more solubilisation of sparingly soluble or less soluble drug molecules. Cosolvents generally possess non-polar regions which do not interact strongly with water and they decrease the capability of water molecules to squeeze out non-polar solutes from the aqueous system [11]. A relationship between the total drug solubility $\left(\mathrm{D}_{\text {tot }}\right)$ and 
cosolvent concentration $(\mathrm{C})$ in a drug-cosolvent-solvent mixture has been described by using the equation, $\log \mathrm{D}_{\text {tot }}=\log \mathrm{D}_{\mathrm{u}}+$ $\sigma \mathrm{C}[12,13]$ where, $\mathrm{D}_{\mathrm{u}}$ and $\sigma$ are drugs solubility in water and cosolvent solubilisation power, respectively. The value of $\sigma$ is inversely correlated with the polarities of both the solute and the cosolvent. The more non-polar the solvent and the solute, the larger is the $\sigma$ value [14].

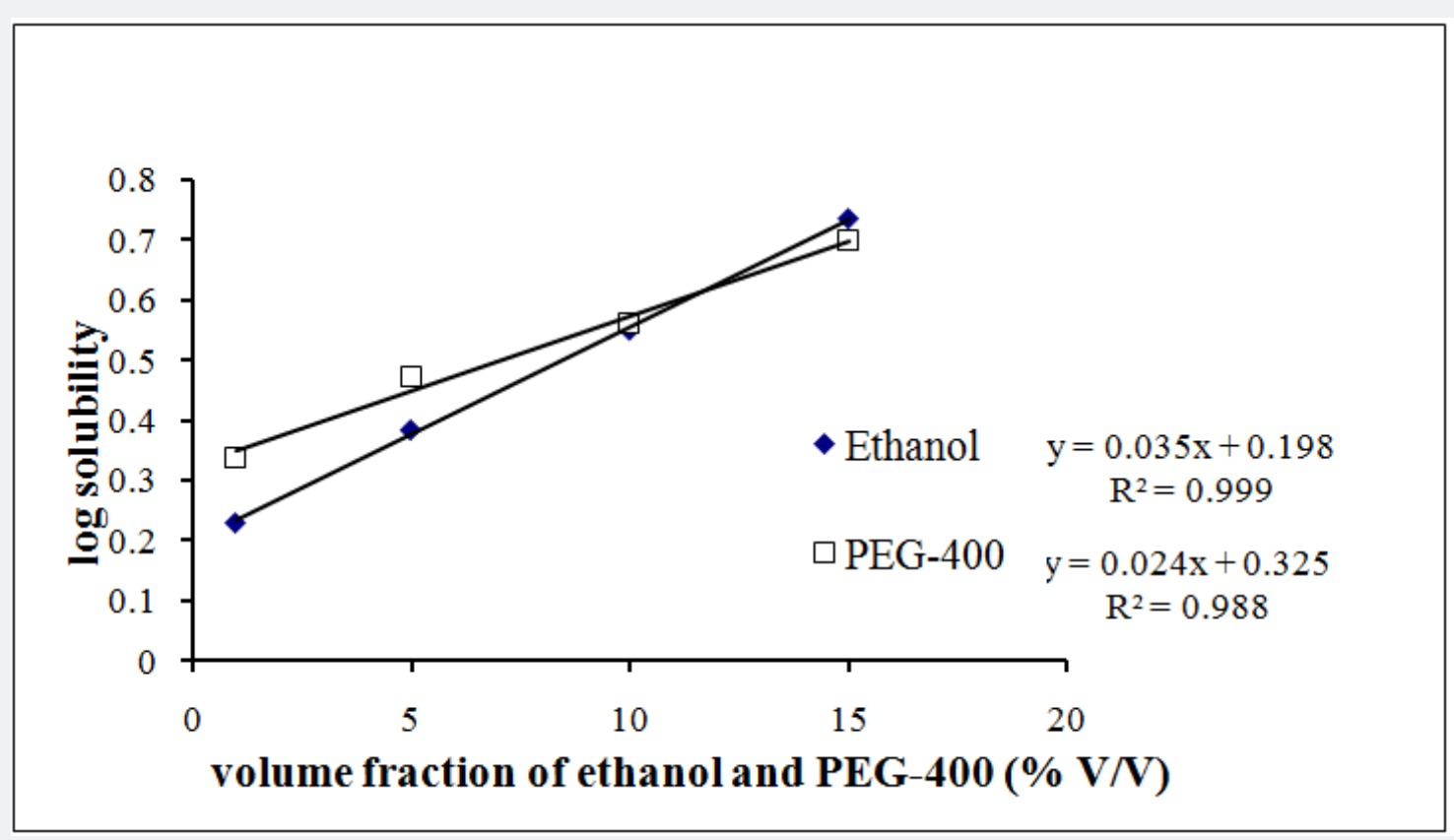

Figure 1: Effect of cosolvency (by ethanol and PEG- 400) on tamoxifen solubility at $37^{\circ} \mathrm{C}$

Figure1 shows straight lines in semi-logarithmic plot of TC solubility vs volume fractions of the experimental cosolvents. The findings suggest exponential increase in TC solubility with the increasing concentration of the cosolvent, ethanol and PEG400. Both ethanol and PEG-400 obey $1^{\text {st }}$ order solubilisation kinetic. For a single non-polar solute, cosolvent solubilisation power ' $\sigma$ ' depends only on cosolvent polarity [14]. Table 1 indicates that solubility enhancement of TC follows the cosolvent order as: EtOH ( $\sigma: 0.036)>$ PEG-400 ( $\sigma: 0.025)$. The less polar is the cosolvent, the more effective it is at disrupting hydrogen bonding interactions in water molecules [15]. In the present study, more efficient improvement of solubility of TC by ethanol may be because ethanol is the less polar solvent than PEG-400 [14].

Table 1: Solubilisation parameters for tamoxifen citrate.

\begin{tabular}{|c|c|c|}
\hline Solubilizing agent & Concentration & Dependence of $\mathrm{D}_{\text {tot }}$ on Du \\
\hline Ethanol $(\% \mathrm{v} / \mathrm{v})$ & $1,5,10,15$ & $\sigma: 0.036$ \\
\hline PEG-400 $(\% \mathrm{v} / \mathrm{v})$ & $1,5,10,15$ & $\kappa: 025$ \\
\hline Tween- $80\left(\mathrm{mmol} \mathrm{L}^{-1}\right)$ & $0.8246,2.0615,4.123,8.24$ & $\kappa: 2.28$ \\
\hline Poloxamer- $407\left(\mathrm{mmol} \mathrm{L}^{-1}\right)$ & $0.082,0.205,0.409,0.818$ & $\kappa: 0.25$ \\
\hline Poloxamer- $188\left(\mathrm{mmol} \mathrm{L}^{-1}\right)$ & $0.12,0.29,0.58,1.16$ & $\mathrm{~K}_{1: 1}=0.48$ \\
\hline BCD $\left(\mathrm{mmol} \mathrm{L}^{-1}\right)$ & $0.4404,0.8809,2.202,4.404$ & $\mathrm{~K}_{1: 1}=0.68$ \\
\hline HPBCD $\left(\mathrm{mmol} \mathrm{L}^{-1}\right)$ & $0.357,0.71428,1.785,3.5714$ & \\
\hline
\end{tabular}

$D_{\text {tot }}$ - total drug solubility in a mixed solvent and cosolvent concentration (C). $D_{u}$ - drug solubility in water. BCD: $\beta$-cyclodextrin; HPBCD: hydroxyl propyl- $\beta$-cyclodextrin.

\section{Micellization}

Figure 2 shows the effects of poloxamer-407, poloxamer-188 and Tween 80 on solubility profiles of TC, respectively which indicates that TC solubility was enhanced in the surfactant order as: poloxamer-407 (5.36-fold) $>$ Tween80 $(5.30$-fold $)>$ poloxamer-188 (3.20-fold). 


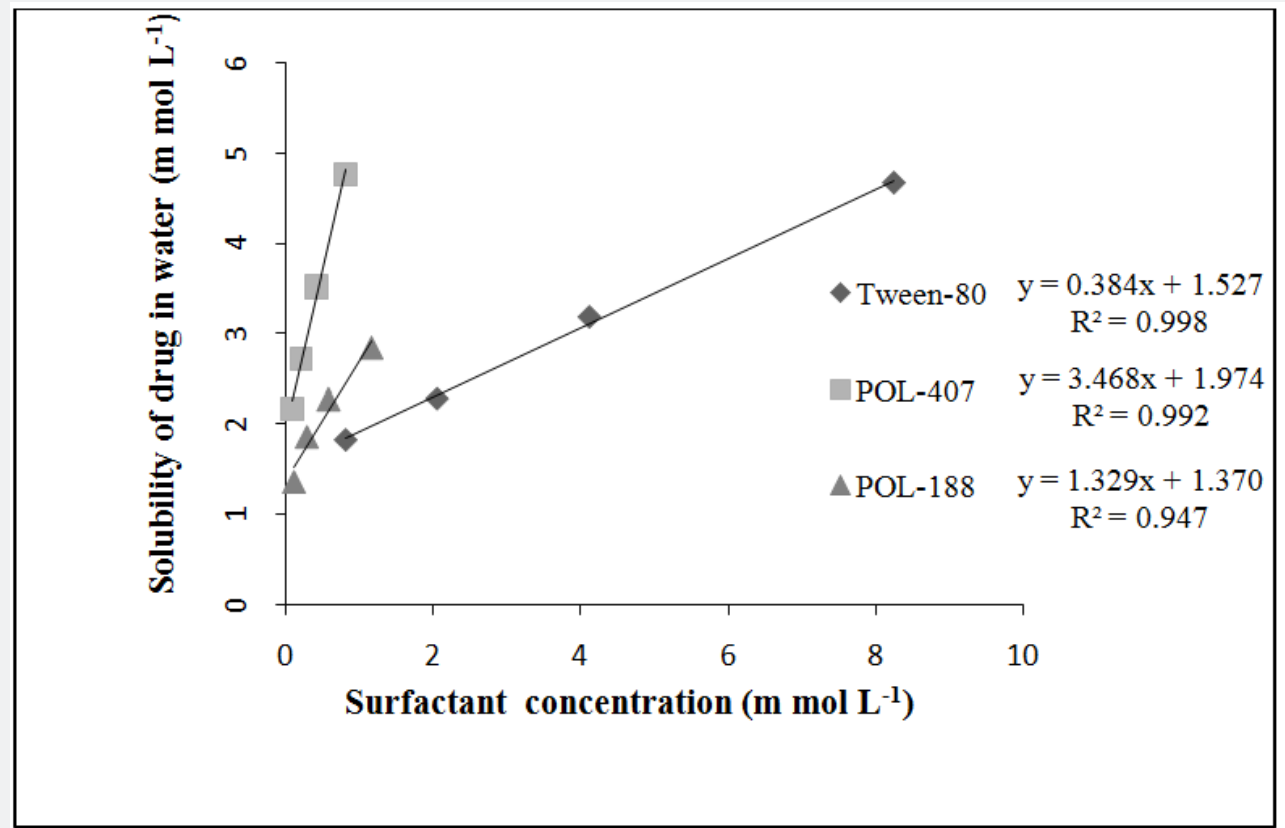

Figure 2: Effect of surfactants (Tween-80, POL-407, POL-188) on tamoxifen solubility at $37^{\circ} \mathrm{C}$

Micelle formation is one of the important mechanisms to solubilise solutes. Incorporation of solute molecules to the micelles depends on the degree of non-polarity of solutes and their micellar partitioning performances [11].The more nonpolar the solute, the more likely it is to be incorporated near the nonpolar core or center of micelles [11]. Researchers have described a relationship of micellar surfactant concentration and solubility of solute (drug) $[15,16]$. Total drug solubility $\left(D_{\text {tot }}\right)$ depends on inherent solubility $\left(D_{u}\right)$ and concentration of micellar surfactant (S) (i.e., the total surfactant concentration minus the critical micellar concentration) and is presented by $\mathrm{D}_{\text {tot }}=\mathrm{D}_{\mathrm{u}}+\kappa \mathrm{D}_{\mathrm{u}} \mathrm{S}[10]$, where $\kappa$ is micellar partition coefficient. Product of $\kappa$ and $D_{u}$ reflects number of surfactant molecules required to solubilise one solute molecule [14].
Table 1 indicates that TC solubility was enhanced in the following sequences: poloxamer-407 ( $\kappa: 2.28)>$ Tween-80 ( $\kappa$ : 0.97 ) > poloxamer-188 ( $\kappa: 0.25$ ). Poloxamer-407 was found to improve the solubility of TC maximally among the surfactants tested. Due to higher micellar partitioning, more non-polar TC molecules were incorporated in the poloxamer-407 micelles.

\section{Complexation}

Figure 3 shows a linear relationship between TC solubility with different concentration of BCD and HPBCD used to solubilize TC. HPBCD showed higher solubilisation of TC than natural BCD. The solubility improvement of TC was about 5.8 -fold with $0.5 \%$ $\mathrm{m} / \mathrm{v}$ BCD and 7.1-fold with $0.5 \% \mathrm{~m} / \mathrm{v}$ HPBCD compared to the original solubility of TC in water.

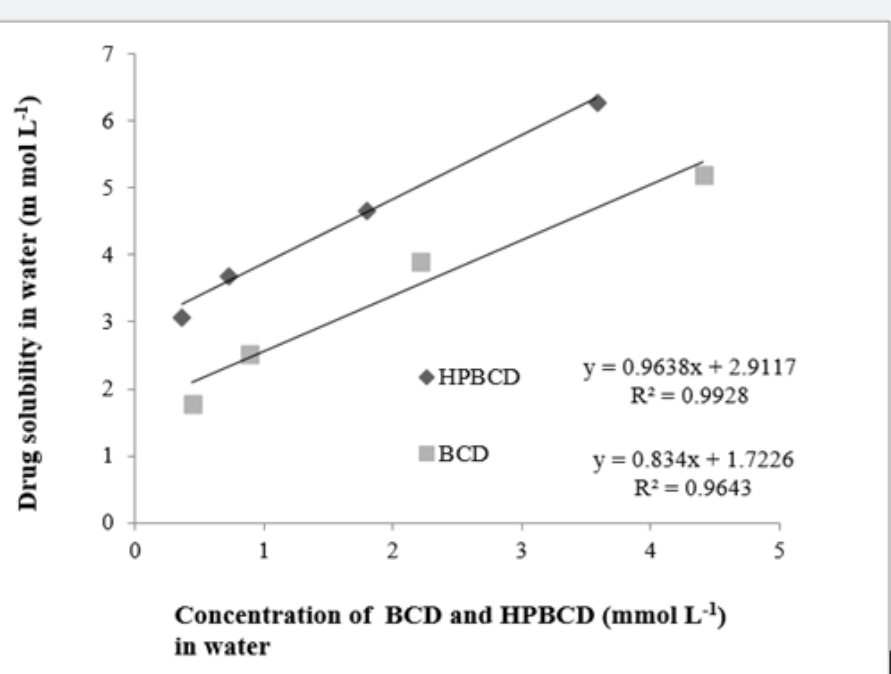

Figure 3: Effect of complexation (by BCD and HPBCD) on tamoxifen citrate solubility at $37^{\circ} \mathrm{C}$ 


\section{Novel Approaches in Drug Designing \& Development}

The solubility of TC with different cyclodextrins has been described using the following equation, $D_{\text {tot }}=D_{u}+K D_{u} L[14]$, where $\mathrm{L}$ is the total ligand concentration, and $\mathrm{K}$ is the complexation constant/ solubilisation capacity of the drug-ligand complex. $\mathrm{D}_{\text {tot }}$ and $\mathrm{D}_{\mathrm{u}}$ have been described earlier. Table 1 shows that the solubilisation capacity $\mathrm{K}_{1: 1}$ of HPBCD (0.68) is slightly greater than that of natural BCD (0.48). The modified $\beta$-cyclodextrins have been widely used and reportedly have higher solubilisation capacity than natural BCD for most drugs $[17,18]$. Complexation constant or solubilising capacity, $\mathrm{K}$, depends on the geometry and polarity of the solute molecules and compatibility between the solute and the cyclodextrin cavity [15].

Except for differences in size, the overall geometries of the cyclodextrins are similar. Each having a torus equals to the length of the appropriate number of glycosides. The derivatized cyclodextrins are characterized by the nature, position and degree of the substituents and there they differ in the available sites. Size and structure of the molecules are important for formation of inclusion compounds. Structurally smaller drug insertion (as compared to CD cavity) is not energetically favored and for appropriately larger solutes, they can fill most of the CD cavity and form the more stable complexes. Thus, TC solubilisation capacity of HPBCD is higher by forming HPBCDTC inclusion complex than that of BCD. Again, equilibrium analysis of drug cyclodextrin complex within the experimental concentration range (data not shown) was found to be of $1: 1$ stoichiometry which has been reported to happen with a low ligand concentration, as at higher ligand concentration higher order complexes are formed [14]. In conclusion, HPBCD is a better complexation ligand for TC than natural BCD.

\section{Thermodynamic Parameters}

Thermodynamic parameters calculated are shown in Table 1. It shows the effect of increasing experimental temperatures and concentrations of both the cyclodextrins on TC solubilisation. The solubility of TC was increased with both the conditions. TC solubility was characterized by a negative $\Delta \mathrm{G}^{\circ}$, indicative of spontaneous dissolution and positive $\Delta \mathrm{H}^{\circ}$ indicative of endothermic dissolution [19]. Van der Waal interactions, hydrogen bonding, hydrophobic interactions, release of highenergy water molecules from the cavity of cyclodextrin and release of strain energy in the ring of cyclodextrin structure etc. are the known driving forces for the formation of cyclodextrin inclusion complexes with foreign molecules [20]. These interactions cause conformational changes in cyclodextrin structure, dissolvation to complex stability and drug solubility. Breakdown of water structure around a solute creates a higher positive $\Delta S^{\circ}$ and a positive $\Delta \mathrm{H}^{\circ}$ known to be governed by hydrophobic interaction [21]. In the present study dissolution thermodynamics of TC in aqueous BCD and HPBCD were characterized by a positive $\Delta H^{\circ}$ (Figures 4\&5), indicative of endothermic dissolution [19].

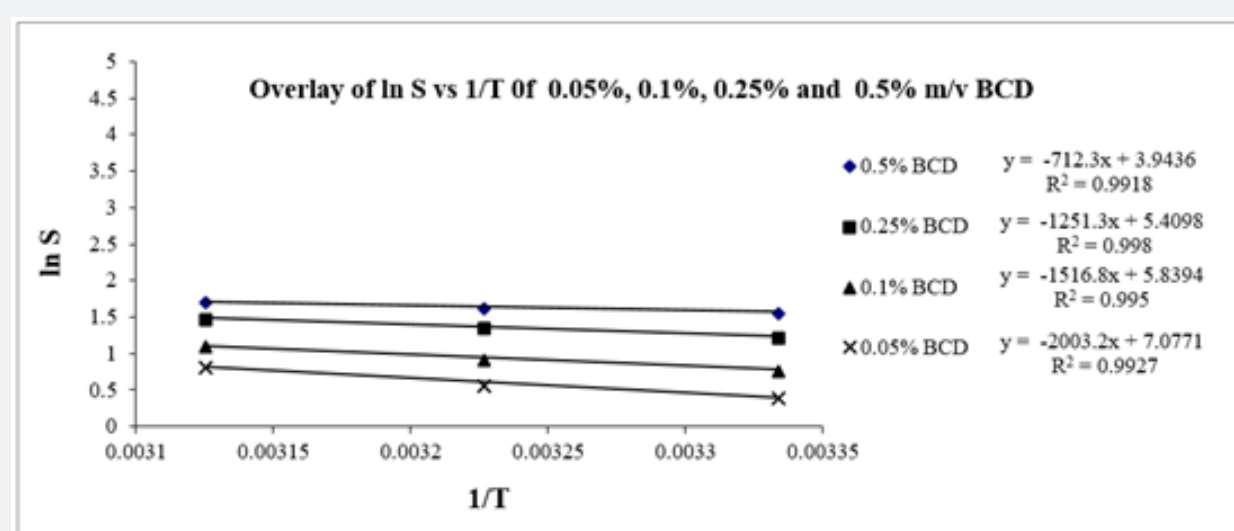

Figure 4: Overlay of In S (of TC) vs 1/T of different concentrations of BCD

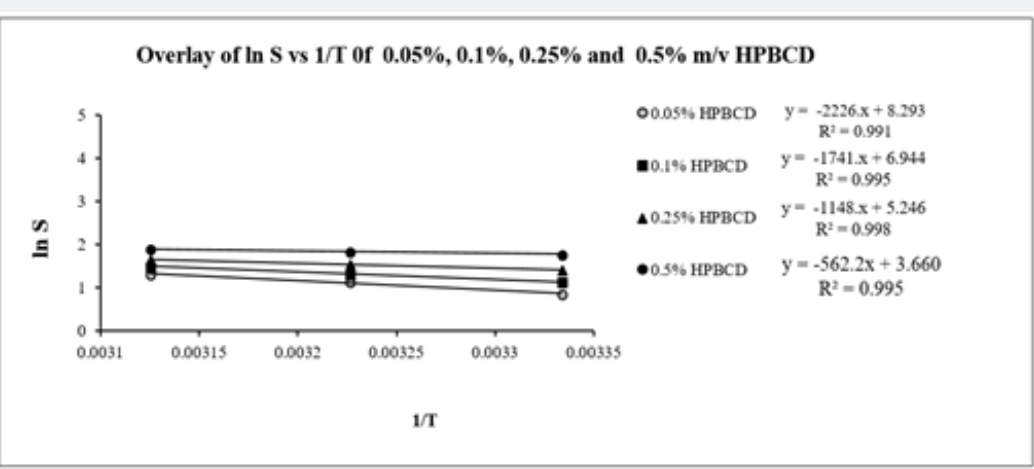

Figure 5: Overlay of In S (of TC) vs 1/T of different concentrations of HPBCD 


\section{Novel Approaches in Drug Designing \& Development}

Reports suggests that complex formation with BCD and HPBCD yields negative or positive $\Delta \mathrm{H}^{\circ}$ and negative or positive $\Delta \mathrm{S}^{\circ}$ [22]. In our study both BCD and HPBCD complex formations resulted in positive $\Delta \mathrm{H}^{\circ}$ as well as positive $\Delta \mathrm{S}^{\circ}$. Breakdown of water structure around TC creates a large positive $\Delta \mathrm{S}^{\circ}$ and a positive $\Delta \mathrm{H}^{\circ}$ (Tables $2 \& 3$ ), apparently governed by hydrophobic interactions [23]. Positive $\Delta S^{\circ}$ for TC may be attributed to transfer of TC from polar aqueous medium to nonpolar cavities of CDs [18]. Positive $\Delta \mathrm{H}^{\circ}$ indicates endothermic dissolution thermodynamics of TC in aqueous BCD and HPBCD. In this experiment, the enthalpy difference $\left(\Delta \mathrm{H}^{\circ}\right)$ decreased with the increasing concentrations of BCD and HPBCD.

Table 2: Enthalpy-Entropy data of tamoxifen citrate-BCD complexation.

\begin{tabular}{|c|c|c|c|c|}
\hline $\begin{array}{c}\text { Concentration } \\
\text { ofcyclodextrin } \\
(\% \mathrm{~m} / \mathrm{v})\end{array}$ & Slope & $\begin{array}{c}\text { Enthalpy }\left(\Delta \mathrm{H}^{\circ}=\text { slope } \times \mathrm{R}\right) \\
\mathrm{kJ} \mathrm{mol}^{-1}\end{array}$ & Intercept & $\begin{array}{c}\text { ENTROPY } \\
\left(\Delta \mathrm{S}^{\circ}=\mathrm{intercept}^{\mathrm{in}} \times \mathbf{R}\right) \mathrm{kJ} \\
\mathrm{mol}^{-1} \mathrm{~K}^{-1}\end{array}$ \\
\hline 0.5 & -712.3 & 5.922276 & 3.9436 & 0.032788 \\
\hline 0.25 & -1251.3 & 10.40368 & 5.4098 & 0.044979 \\
\hline 0.1 & -1516.8 & 12.61113 & 5.8394 & 0.048551 \\
\hline 0.05 & -2003.2 & 16.65521 & 7.0771 & 0.058841 \\
\hline
\end{tabular}

Table 3: Enthalpy-Entropy data of Tamoxifen citrate-HPBCD complexation.

\begin{tabular}{|c|c|c|c|c|}
\hline $\begin{array}{l}\text { Concentration of } \\
\text { cyclodextrin }(\% \mathrm{~m} / \mathrm{v})\end{array}$ & Slope & Entalpy $\left(\Delta H^{\circ}=\right.$ slope $\left.\times R\right) \mathrm{kJmol}^{-1}$ & Intercept & $\begin{array}{c}\text { ENTROPY } \\
\left(\Delta S^{\circ}=\text { intercept }^{\text {int }) \mathrm{k}}\right] \\
\mathrm{mol}^{-1} \mathrm{~K}^{-1}\end{array}$ \\
\hline 0.5 & -562.25 & 4.67 & 3.66 & 0.03 \\
\hline 0.25 & -1148.3 & 9.54 & 5.25 & 0.043 \\
\hline 0.1 & -1741.1 & 14.47 & 6.94 & 0.058 \\
\hline 0.05 & -2226.7 & 18.51 & 8.29 & 0.069 \\
\hline
\end{tabular}

This is favourable for a thermodynamic process to happen and in this case, enthalpy was the driving force for complexation of TC with BCD and HPBCD. The entropy difference $\left(\Delta S^{\circ}\right)$ decreased with (Tables 2\&3) increasing BCD and HPBCD concentrations. The entropy was not the driving force for complexation of TC with CDs. With respect to the HPBCD, the complexation of natural BCD with TC is characterized by less positive enthalpy, the contribution from which the solubility improvement profile of TC with BCD is lesser than HPBCD.

\section{Pharmacokinetic Assay}

The study result of pharmacokinetic assay by LC-MS/MS was represented by the plasma concentration-time profile (Figure 6).The pharmacokinetic parameters of tamoxifen as a free drug (FD) and along with a solubility enhancer HPBCD (HCD) (Table 4) revealed that Area under the curve (AUC) and maximum concentration reached $\left(\mathrm{C}_{\max }\right)$ for tamoxifen was much higher in case of CD than FD which indicated that cyclodextrin had a clear effect on improving the bioavailability of tamoxifen

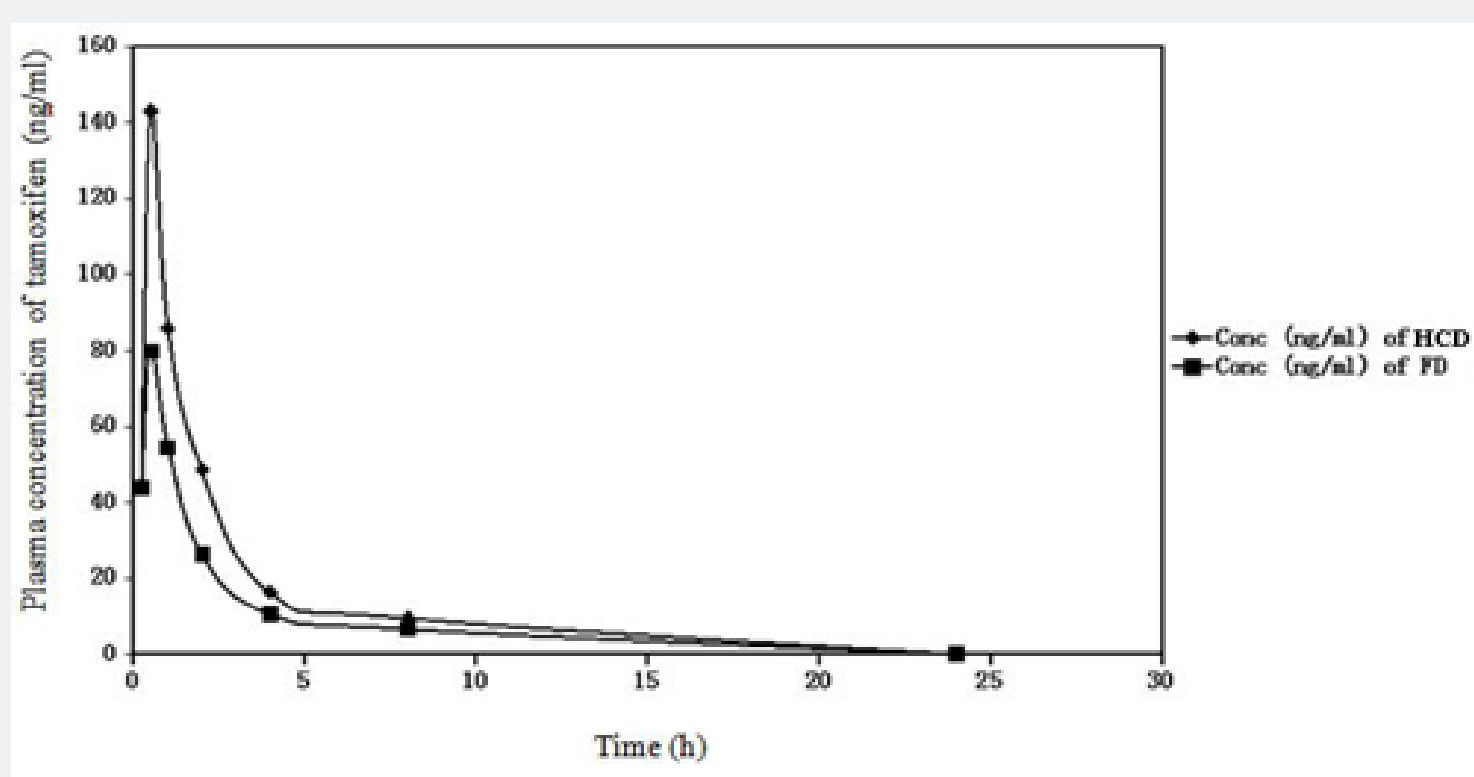

Figure 6: Plasma concentration time curves of tamoxifen as a free drug (FD) and along with a solubility enhancer HPBCD (HCD) 
Table 4: Pharmacokinetic parameters of tamoxifen after oral administration of tamoxifen $(10 \mathrm{mg} / \mathrm{kg})$ with HCD in mice

\begin{tabular}{|c|c|c|}
\hline \multirow{2}{*}{ Parameters } & Plasma values of Tamoxifen upon oral administration & \multicolumn{2}{|c|}{ FD } \\
\cline { 2 - 3 } & HCD & 2.75 \\
\hline Half-life $(\mathrm{h})$ & 3.28 & 79.9 \\
\hline $\mathrm{C}_{\text {max }}(\mathrm{ng} / \mathrm{ml})$ & 143 & 0.5 \\
\hline $\mathrm{T}_{\text {max }}(\mathrm{h})$ & 0.5 & 171.6 \\
\hline $\mathrm{AUC}_{0-\mathrm{t}}$ & 275.6 & 203.4 \\
\hline $\mathrm{AUC}_{0-\text { inf }}$ & 313.4 & 166.6 \\
\hline $\mathrm{CL}(\mathrm{L} / \mathrm{h} / \mathrm{kg})$ & 108.9 & 2.91 \\
\hline $\mathrm{MRT}_{\text {inf }}(\mathrm{h})$ & 2.97 & \multicolumn{2}{|c|}{2.9} \\
\hline
\end{tabular}

Mean $\pm S D(n=6), A U C$; area under the plasma concentration time curve from $0 \mathrm{~h}$ to infinity, $C_{\max }$; peak concentration, $T_{\max }$; time to reach the peak concentration, MRT; mean residence time; CL; total body clearance. HCD; hydroxy propyl $\beta$ cyclodextrin added to tamoxifen, FD; tamoxifen as a free drug.

On other hand, clearance rate was higher for FD in comparison with HCD which may be due to the faster elimination of tamoxifen when administered alone (FD) than with a solubility enhancer (HCD). After in vivo administration, free tamoxifen due to its poor solubility was absorbed less but eliminated quickly after absorption. On the other hand, tamoxifen-HPBCD complex was absorbed faster and distributed in the system with a slower elimination.

\section{Conclusion}

The water solubility of TC was increased 7.1-fold in the presence of $0.5 \% \mathrm{~m} / \mathrm{v}$ HPBCD, compared to $0.5 \% \mathrm{~m} / \mathrm{v}$ natural BCD (increase 5.8-fold). Thermodynamic parameters derived from TC solubility in the presence of various concentrations of BCD and HPBCD at several temperatures reveal that the solubility of TC increased with an increase in temperature. Besides, TCBCD complex formation was a characteristic of a very strong hydrophobic interaction. Furthermore, pharmacokinetic study was also representing the similar observation with higher Area under the plasma concentration-time curve and peak plasma concentrations of TC, when administered along with HPBCD. However, clinical trial will be needed to conclude the simultaneous oral administration of cyclodextrin along with tamoxifen to enhance the bioavailability in human.

\section{Acknowledgement}

We acknowledge the funding agency University Grants Commissions, Government of India and Indian Council of Medical Research (ICMR), Grant number: Nan/BMS -45/6/2013 for providing the necessary grants for the study.

\section{Disclosure}

The authors report no conflicts of interest in this work.

\section{References}

1. JK Sarmah, SK Bhattacharjee, R Mahanta (2009) Preparation of crosslinked guar gum nanospheres containing tamoxifen citrate by single step emulsion in situ polymer cross-linking method. J Incl Phenom Macrocycl Chem 65(3-4): 329-334.
2. MMT Buckley, KL Goa (1989) Tamoxifen: a reappraisal of its pharmacodynamic and pharmacokinetic properties and therapeutic use, Drugs 37(4): 451-490.

3. EA Lien, E Solheim, OA Lea (1989) Distribution of 4-hydroxy-Ndesmethyl tamoxifen and other tamoxifen metabolites in human biological fluids during tamoxifen treatment. Cancer Res 49(8): 21752183.

4. VM Rao, J Haslam, VJ Stella (2001) Controlled and complete release of a model poorly water-soluble drug, prednisolone, from hydroxypropyl methylcellulose matrix tablets using (SBE) (7m)-beta-cyclodextrin as a solubilizing agent. J Pharm Sci 90(7): 807-816.

5. Indian Pharmacopoeia (1996) Ministry of Health and Family Welfare, Government of India, Published Delhi, India, p. 1.

6. SM Ahmed (1998) Improvement of solubility and dissolution of 19-Norprogesterone via inclusion complexation, Jour. Inclusion. Phen Mol Recog Chem 30(2): 111-125.

7. S Sehra, AS Dhake (2005) Formulation and evaluation of sustained release microspheres of poly-lactide-co-glycolide containing tamoxifen citrate, J Microencapsul 22(5): 521-528.

8. Al Omari, MM Zughul, MB Davies, JED Badwan (2006) Sildenafil/ cyclodextrin complexation: stability constants, thermodynamics, and guest-host interactions probed by $1 \mathrm{H}-\mathrm{NMR}$ and molecular modeling studies, J. Pharm. Biomed. Anal. 41(3): 857-865.

9. JS Choi, KW Kang (2008) Enhanced tamoxifen bioavailability after oral administration of tamoxifen in rats pretreated with naringin, Arch Pharm Res. 31(12): 1631-1636.

10. SH Yalkowsky (1999) Solubility and Solubilization in Aqueous Media, Oxford University Press, New York, USA.

11. Y Ran, L Zhao, Q Xu, SH Yalkowsky (2001) Solubilization of Cyclosporin A, AAPS Pharm Sci Tech 2(1): 2.

12. S H Yalkowsky, TJ Roseman, NY Dekker Solubilization of drugs by cosolvents. In Techniques of Solubilization of Drugs, New York 1981.

13. SH Yalkowsky, SH, JT Rubino (1985) Solubilization of cosolvents I: organic solutes in propylene glycol-water mixtures, J. Pharm. Sci 74(4): 416.

14. J Swarbrick, JC Boylan (2002) Encyclopedia of Pharmaceutical Technology, $2^{\text {nd }}$ edition, Informa Health Care, Volume 3.

15. L Zhao, P Li, SH Yalkowsky (1999) Solubilization of fluasterone, J. Pharm. Sci. 88(10): 967-969. 
16. D Attwood, AT Florence, Surfactant systems, New York, Chapman and Hall, 1983.

17. J Pitha, J Milecki, H Fales, L Pannel, K Uekama (1986) Hydroxypropyl$\beta$-cyclodextrin: preparation and characterization: effects on solubility of drugs. Int J Pharm 29(1): 73-82.

18. K. Uekama, M Otagiri (1987) Cyclodextrins in therapeutic drug carrier systems, in CRC Critical Reviews in Therapeutic Drug Carrier Systems, 3(1):1-40.

19. Z Zuo, G Kwon, B Stevenson, J Diakur, LL Wiebe (2000) Flutamide - hydroxypropyl-ß-cyclodextrin complex: formulation, physical characterization, and absorption studies using the caco- 2 in vitro model, J. Pharm. Pharm. Sci 3(2): 220-227.
20. M Komiyama, LM Bender (1983) Importance of apolar binding in complex formation of cyclodextrins with adamantanecarboxylate, J Am Chem Soc 100(7): 2259-2260.

21. T Loftsson, E M Brewster (1996) Pharmaceutical application of cyclodextrins: Drug solubilization and stabilization, J. Pharm. Sci. 85(10): 1017-1025.

22. IV Terekhova, TV Volkova, GL Perlovich (2006) Experimental analysis of complex formation of Niflumic acid with $\boldsymbol{\beta}$-cyclodextrins. J Incl Phen Macro Chem 55(3-4): 335-340.

23. A Martin (1993) Physical Pharmacy, (4th edn), Lea \& Febiger, Philadelphia, USA, pp. 274-277.

\section{Your next submission with Juniper Publishers will reach you the below assets}

- Quality Editorial service

- Swift Peer Review

- Reprints availability

- E-prints Service

- Manuscript Podcast for convenient understanding

- Global attainment for your research

- Manuscript accessibility in different formats ( Pdf, E-pub, Full Text, Audio)

- Unceasing customer service

Track the below URL for one-step submission https://juniperpublishers.com/online-submission.php 